\title{
NCLEX RN Exam: A university school of nursing case study of preparation strategies
}

\author{
Kathryn Puskar , Melissa Rudolph, Xiaojun Shi \\ School of Nursing, University of Pittsburgh, Pittsburgh, United States
}

Received: May 4, 2017

Accepted: June 1, 2017

Online Published: June 19, 2017

DOI: $10.5430 /$ jnep.v7n11p37

URL: https://doi.org/10.5430/jnep.v7n11p37

\begin{abstract}
The NCLEX-RN (National Council Licensure Examination-Registered Nurse) is the exam taken at the end of a U.S. nursing student's education to enable him or her to become a licensed registered nurse. The purpose of this article is twofold (1) to discuss NCLEX-RN preparation strategies provided by several U.S schools of nursing; and (2) to describe a case study focusing on a university school of nursing's preparation strategies implemented to improve NCLEX RN pass rate. Specific actions and results from case study may be useful to other nurse educators teaching in baccalaureate school of nursing.
\end{abstract}

Key Words: NCLEX, Nursing students, Preparation strategies

\section{INTRODUCTION}

The NCLEX-RN (National Council Licensure Examination-Registered Nurse) has undergone numerous changes over the past few years, which include different question formats and an emphasis on critical thinking skills. What this means for nursing students and schools of nursing is the adoption of different tactics to prepare for the new version of the exam. For example, the NCLEX-RN pass rates among BSN students at one university school of nursing declined from $91.36 \%$ in 2012 to $80.18 \%$ in 2013, which suggested that the students were not accustomed to the new version of the exam. After the school implemented different forms of support to assist its students in preparing for the new version of the exam, the NCLEX-RN pass rate among the students increased to its current level of $97 \%$. The purpose of this paper is to present the strategies implemented by the school that resulted in the improved NCLEX-RN outcomes among its BSN students.

The NCLEX-RN has evolved with time and changes in nurs- ing practice. The passing standards change every 3 years, which has resulted in not only a decline in NCLEX-RN pass rates from a national average of a $90.22 \%$ in 2012 to $84.29 \%$ in $2013,{ }^{[1]}$ but also the implementation of remediation tactics among U.S. schools of nursing to assist their students in passing the exam. It is against this backdrop that we conducted a literature review to analyze the types of NCLEX-RN remediation and their efficacy among U.S. schools of nursing. The remediation tactics that have been used include (1) anxiety relief methods, (2) standardized exams that require remediation if a student scores below a defined standard, and (3) a pedagogical emphasis of nursing concepts and critical thinking skills.

In its current form, the NCLEX-RN is a computerized, adaptive testing model. The exam can be as short as 75 questions yet can take as long as 6 hours to complete. Test takers must pay approximately US $\$ 200.00$ to register for the NCLEX$\mathrm{RN}$. The test is adaptive, which means that it begins with easier questions and becomes more difficult as the test pro-

*Correspondence: Kathryn Puskar; Email: Krp12@pitt.edu; Address: School of Nursing, University of Pittsburgh, Pittsburgh, United States. 
gresses. More challenging questions are presented at the end of the exam, where the test designers assume that test takers have a $50 \%$ chance of correctly answering the questions. ${ }^{[2]}$ Moreover, all NCLEX-RN questions now generally require more critical thinking to answer than they previously did by requiring test takers to select all answers that apply to correctly answer questions targeting, for example, nursing diagnoses and nursing.

In 2013, the National Council of State Boards of Nursing (NCSBN) announced the content areas that would be covered on the NCLEX-RN, which currently comprise management of care (17\%-23\%), safety and infection control (9\%-15\%), health promotion and maintenance (6\%-12\%), psychosocial integrity (6\%-12\%), basic care and comfort (6\%-12\%), pharmacological and parenteral therapies (12\%-18\%), reduction of risk potential $(9 \%-15 \%)$, and physiological adaptation (11\%-17\%). ${ }^{[1]}$ Questions related to these fundamental content areas could be asked of all types of patients and patient populations and particular nursing specialties (e.g. pediatrics, OB/GYN, mental health, geriatrics, medical-surgical). ${ }^{[2]}$ The NCSBN Board of Directors raised the passing standard was raised from - 0.16 logits to 0.00 logits in December 2012 for the NCLEX-RN. Logit means the unit of measurement to report relative differences between student's ability and the question difficulties.

\section{NCLEX-RN PREPARATION STRATEGIES PROVIDED BY U.S. SCHOOLS OF NURSING}

A review of the literature reveals that several strategies have been used by U.S. schools of nursing to help their students prepare of the NCLEX-RN.

Long Island University, School of Nursing improved its NCLEX-RN pass rates from $70 \%$ to $93 \%$. To accomplish this, the school used a standardized midterm and final exam in each clinical course. Using a standard test style helps students acclimate to the types of questions that will be asked once they eventually take the NCLEX-RN. The idea is that they would gain a better understanding of what they need to improve before taking the NCLEX-RN. Moreover, remedial courses were offered if passing scores were not met. Additionally, an NCLEX-RN review course was offered, and the school purchased a self-paced online course for the students. ${ }^{[3]}$

York College improved its NCLEX-RN pass rates from $83 \%$ to $94.9 \% .{ }^{[2]}$ To accomplish this, the school deployed a computerized examination at the end of senior year that required a score of 850 or better to pass. If a score of 850 was not achieved after two attempts, a student would be assigned remedial work (e.g., practice questions, test-taking strategy lectures) and required to meet with members of the faculty to keep track of progress and make sure they are ready for the NCLEX-RN. ${ }^{[4]}$ York College also placed more emphasis on critical thinking scenarios as assignments outside class to assist its students in achieving higher NCLEX-RN scores. ${ }^{[4]}$

The University of Wisconsin-Eau Claire improved its NCLEX-RN pass rates from $83.87 \%$ to $91.11 \%^{[2]}$ through the use of two methods. First, an RN assessment, independent study module was used during the second semester of senior year that featured reading assignments on test-taking tips in an NCLEX-RN review book and online practice quizzes. Second, a simulated NCLEX-RN exam was given within the last 6 weeks of senior year. ${ }^{[5]}$

Penn State Erie improved its NCLEX-RN pass rates from $92 \%$ in 2010 to $95 \%$ in $2014 .^{[2]}$ To accomplish this, the school did not change test rigor; instead, it chose to have students engage nursing concepts rather than master knowledge. ${ }^{[6]}$ For example, mastering knowledge is simply knowing what a drug does, or what the risk factors for lung cancer are. Nursing concepts include: providing basic care and comfort, maintaining psychosocial integrity, providing safe care, and managing care effectively.

At Western Governors University, NCLEX-RN pass rates increased from $73 \%$ in 2013 to $81.5 \%$ in $2014 .{ }^{[2]}$ This increase was facilitate by the university by implementing an NCLEX-RN boot-camp, which had its nursing students sleeping 8 hours a night, exercising every day, completing 500 NCLEX-RN questions a day, and utilizing other methods (e.g., stretching, guided imagery, avoiding caffeine) to help the students reduce their anxiety. ${ }^{[7]}$

At the University of St. Francis, NCLEX-RN pass rates improved from $83 \%$ in 2010 to $100 \%$ in $2014 .^{[2]}$ This was accomplished through the purchase of the Assessment Technologies Institute (ATI) Comprehensive Assessment and Remediation Package, which enabled students to complete tests after every course starting from freshman year. ${ }^{[8]}$ The results are showed by Table 1 .

Finally, in an analysis of school efforts to increase NCLEXRN pass rates, Hyland found that when minorities (e.g. black) were grouped together, NCLEX-RN pass rates improved. Moreover, Hyland reports that (1) NCLEX-RN study materials should be provided at low cost to students, (2) the HESI (Health Education Systems Incorporated) is an accurate predictor of NCLEX-RN success, and (3) student test anxiety issues should be addressed to promote achieving higher NCLEX-RN scores. Furthermore, standardized testing, curricular changes, and test preparation have a proven effect in improving test scores across the board among schools of nursing. ${ }^{[9]}$ 
Table 1. US Nursing Schools strategies to improve NCLEX scores

\begin{tabular}{|c|c|c|}
\hline School & Score $(\%)$ & Strategies \\
\hline \multirow{3}{*}{ Long Island University } & \multirow{3}{*}{70 to 93} & Standardized Exam \\
\hline & & Remedial Courses \\
\hline & & Review Courses \\
\hline \multirow{3}{*}{ York College } & \multirow{3}{*}{83 to 94.9} & Exam at end of senior year \\
\hline & & Remedial Work \\
\hline & & Emphasis on critical thinking assignment \\
\hline \multirow{3}{*}{ University Wisconsin-Eau Claire } & \multirow{3}{*}{83.87 to 91.11} & Assessment Module \\
\hline & & Test Taking Tips \\
\hline & & Simulated NCLEX Exam \\
\hline Penn State Erie & 92 to 95 & $\begin{array}{l}\text { Emphasis on nursing concepts instead of factual } \\
\text { knowledge }\end{array}$ \\
\hline \multirow{2}{*}{ Western Governors University } & \multirow{2}{*}{73 to 81.5} & NCLEX Boot-camp \\
\hline & & Use of guided imagery to reduced test anxiety \\
\hline University of St. Francis & 83 to 100 & $\begin{array}{l}\text { Use of Assessment Technologies Institute (ATI) } \\
\text { Complete practice test every year }\end{array}$ \\
\hline
\end{tabular}

Finally, in an analysis of school efforts to increase NCLEX$\mathrm{RN}$ pass rates, Hyland found that when minorities (e.g. black) were grouped together, NCLEX-RN pass rates improved. Moreover, Hyland reports that (1) NCLEX-RN study materials should be provided at low cost to students, (2) the HESI (Health Education Systems Incorporated) is an accurate predictor of NCLEX-RN success, and (3) student test anxiety issues should be addressed to promote achieving higher NCLEX-RN scores. Furthermore, standardized testing, curricular changes, and test preparation have a proven effect in improving test scores across the board among schools of nursing. [9]

Helping student learn to handle test anxiety is advocated as a strategy. Understanding that anxiety can be motivated and utilizing techniques of deep breathing, visualization, and positive reframing are useful techniques to help students' test performance. Poorman with STAT Nursing Consultants over 30 years conducts faculty workshops and assists student nurse to utilize cognitive strategies to monitor test anxiety. ${ }^{[10]}$

Many nursing schools regard HESI as a good strategy to help their students improve NCLEX test scores. HESI is a comprehensive exam with 160 questions consisted of multiple choices, multiple response, fill-in-blank, which reflects the real format of the NCLEX test. Barton, Willson, Langford and Schreiner found that HESI can predict the results of students' NCLEX scores with a very high accuracy. In their research, the outcome of HESI and NCLEX of 5438 nursing students which include 3084 associated degree students and 2354 baccalaureate degree students from 99 randomly selected nursing schools were obtained. To improve the students' scores of HESI test, 54 schools in the study established HESI study policy including preparation, retesting, remedi- ation and consequences. $67 \%$ schools in the study require all their students participant the HESI test but with different benchmark and $64 \%$ schools require students to remediate the test if their score lower than the benchmark. The results show that $98.26 \%$ students who have HESI scores higher than 900 can pass the NCLEX test, which is a good indicator to show the high accuracy of the HESI test as a predictor of NCLEX test score. ${ }^{[11]}$

\section{CASE STUdy: NCLEX-RN PREPARATION STRATEGIES PROVIDED BY UNIVERSITY SCHOOL OF NURSING}

\subsection{Proactive remediation strategies}

At the school of nursing, several strategies that provided remediation to better prepare BSN students for taking the NCLEX-RN were implemented. First, proactive remediation guidelines were developed and shared with the faculty and students (see Figure 1). These guidelines "Bridge to NCLEX RN Success" outline a checklist for students to provide a path of study to follow that is designed to promote NCLEX-RN success. As can be seen from Figure 1, each successive year stipulates NCLEX-RN questions and possible remediation that are commensurate with courses offered each semester. The figure also demonstrates how the BSN student has the opportunity of being assigned a tutor for additional support if necessary. Finally, at the end of the senior year, students will be able to attend a Kaplan 4-day review course.

Second, Kaplan tests that provide practice for the NCLEX$\mathrm{RN}$ were integrated into school of nursing core undergraduate courses: Pharmacology and Therapeutics, Foundations of Nursing, Nursing Management of the Adult with Acute/Chronic Health Problems, Nursing Care of Mothers, 
Newborns, and Families, Nursing Care of Children \& Families, Nursing Care of Clients with Psychiatric Mental Health Problems, Advanced Nursing Management of the Adult with Acute/Complex Health Problems, Nursing Care of Older Adults, Community Health Nursing, Advanced Clinical Problem Solving, and Transition into Professional Nursing Prac- tice. A secure predictor practice exam (a standardized exam) was given during the first and last terms of senior year. Finally, a new senior seminar, which targeted test-taking strategies to prepare students for the NCLEX-RN, was developed and made mandatory for all graduating seniors.

\section{NURSING LICENSE SUCCESS}

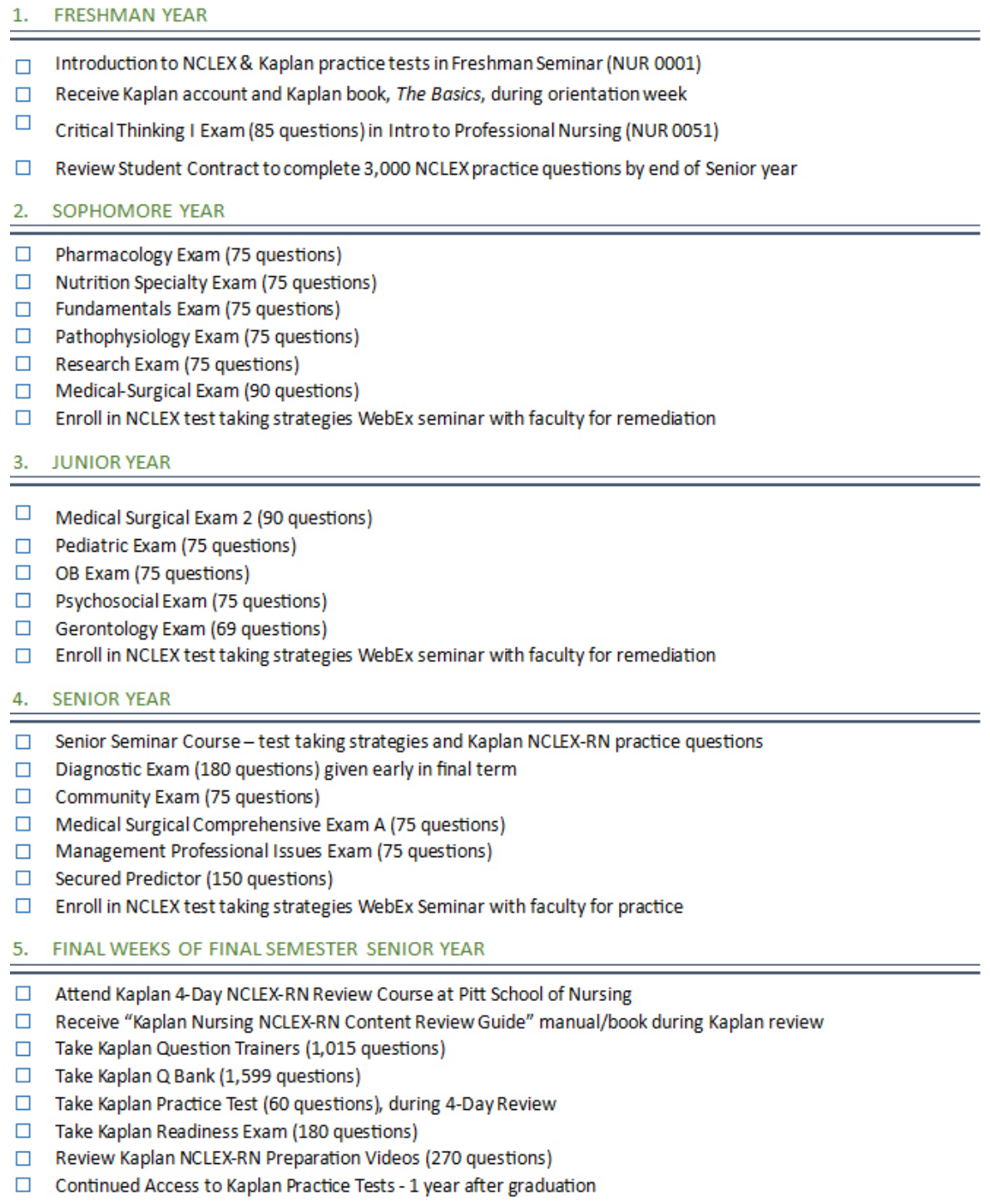

Figure 1. Nursing License Success

Description: Nursing License Success describes strategies to increase pass rate for freshman, sophomore, junior, and senior students

Third, the university school of nursing promoted a new concept as part of its academic culture: the expectation that students could pass the NCLEX as early as freshman year. As part of this promotion, university school of nursing students were sent a congratulatory letter upon admission to the BSN program that included the document NCLEX Strategies for Success (see Figure 2), which introduced and explained this expectation to pass the NCLEX-RN as early in the program as possible. NCLEX Strategies for Success is a resource for incoming students to inform them about what tools are pro- 
vided, free of charge, from the university school of nursing to prepare for the NCLEX-RN. As can be seen from Figure 2 , the document includes Internet resources from the Khan
Academy, practice exams from Health Sciences Library, and three smartphone applications that students can download to their mobile devices.

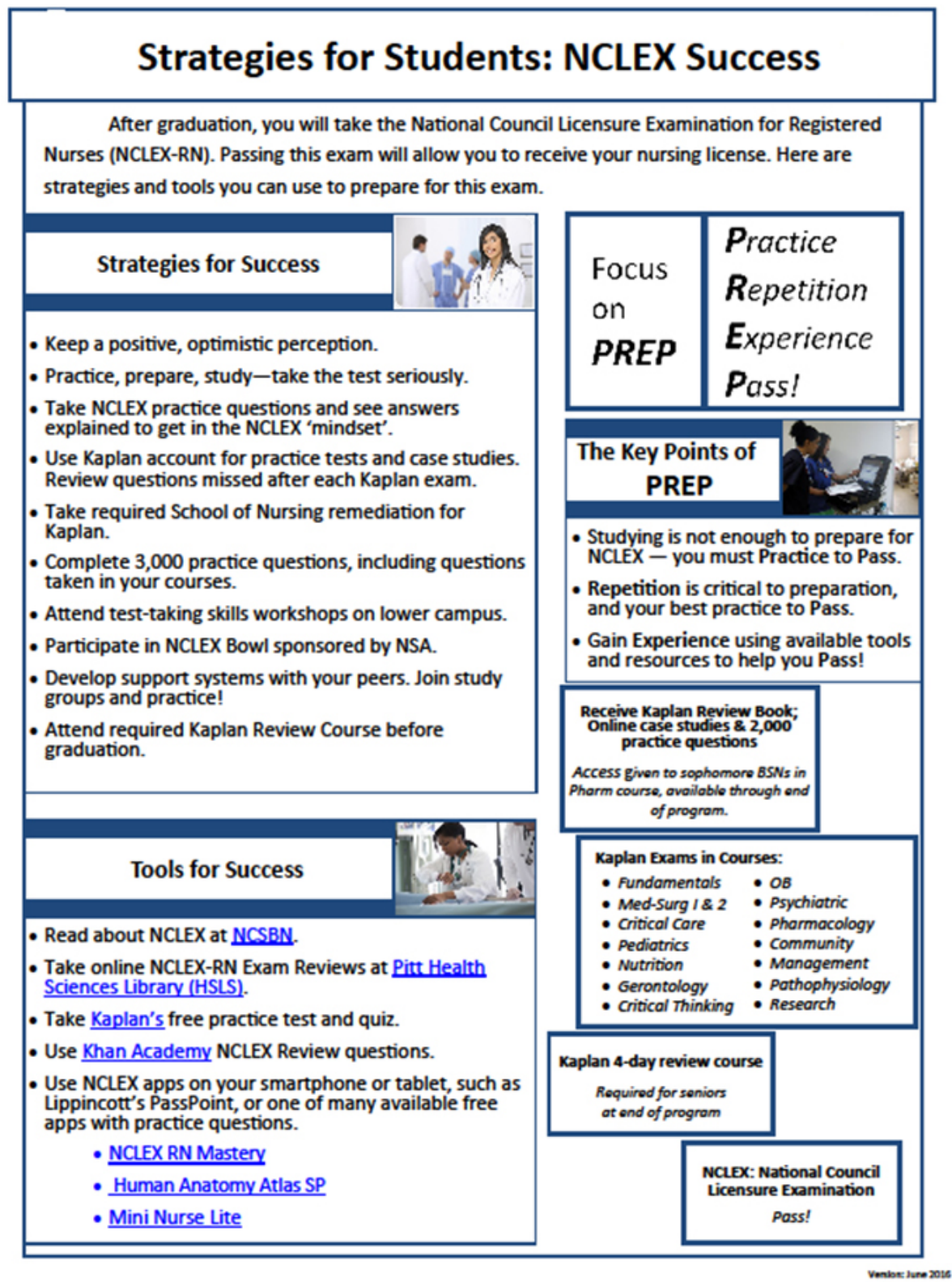

Figure 2. University School of Nursing, Strategies for Student NCLEX Success

Description: Description: Strategies for Success was developed by students and includes practice tools and tips in preparing for NCLEX

\subsection{Additional teaching strategies}

At the University school of nursing, a culture of passing the NCLEX exam on the first-try began with the teaching strategy of a fun learning resource. The resources use of the Monopoly-type board game titled RNteratinment: The NCLEX Examination Review Game was recommended for students/faculty to be part of clinical conferences. The game includes 800 NCLEX-RN clinical questions with rationales: including Health Promotion and Maintenance, Physiological Integrity, Psychosocial Integrity, and Safe and Effective Care Environment. It also features test-taking tips and test-taking traps with helpful strategies.

Another teaching strategy was a simulation video on delegation developed by an university school of nursing faculty member to emphasize the prioritization and delegation of roles by a nurse. The lecture she created included clinical 
scenarios to make the student think critically about either how a health-care worker in charge should react, or what the most effective use of particular health-care workers for particular jobs was. Moreover, placing an emphasis on application type questions was recommended to the university school of nursing faculty for insertion into midterms, practice quizzes, and final exams. Simultaneously, an emphasis on case stud- ies, as a way to encourage students to apply concepts and not just memorize facts, was integrated into university school of nursing courses. Finally, a student contract was devised, which requires students to complete 3,000 NCLEX-RN practice questions during the course of the BSN program (see Figure 3).

\title{
University School of Nursing
}

\author{
Student Contract to complete practice questions \\ in preparation to take Nursing State Board Exam
}

\begin{abstract}
I, as a student pursuing the Bachelor of Science in Nursing degree at the university, contract with the university School of Nursing to complete 3,000 National Council Licensure Exam (NCLEX) practice questions during my baccalaureate education. I will do practice questions each semester in order to complete 3,000 questions before graduating with my BSN degree.
\end{abstract}

I will submit a record to document my 3,000 practice questions to my professor in Senior Seminar or Transition into Professional Nursing Practice.

My signature acknowledges my commitment to the contract, which will help me practice and prepare for passing nursing state boards upon graduation.

\begin{abstract}
Student Signature
Submit this contract along with a document listing the number of practice questions you completed to your professor before graduation.
\end{abstract}

Figure 3. University School of Nursing, Student Contract

Description: figure 3 is a student contract demonstrating students' agreement to do 3,000 NCLEX practice questions over 4 years.

These ambitious teaching and learning strategies ${ }^{[12]}$ were implemented with university school of nursing faculty and student input. The traditional approach to nursing school was passive, teacher-centered learning. Now, University school of nursing is implementing active instruction to students with the remediation opportunities, and having students become familiar with NCLEX-RN style questions early on in their education. The president of the Nursing Student Association provided input into the flyer NCLEX Strategies for Student Success. Faculties were on Boarded to the preparation strategies received consultation from Kaplan for training/orientation, and valued the importance of remediation 
as part of faculty workload. In addition, one faculty was assigned 30\% effort to manage the logistic of Kaplan Prep Testing/Training of students. ${ }^{[13]}$

\section{Conclusion/Summary}

NCLEX-RN pass rates have been shown to improve in schools of nursing with not only the introduction of standardized testing, but also targeted remediation. Moreover, NCLEX-RN preparation materials should be made available free of charge - or at least at a subsidized price - for student use, to encourage students to begin their preparation for exam early and continue it consistently throughout the BSN program. Furthermore, an emphasis should be placed in the nursing curriculum on learning and exercising nursing concepts rather than merely nursing facts. Guiding nursing students on how to think critically and manage test anxiety is imperative in mastering the NCLEX-RN.

Schools of nursing should implement more standardized testing and remediation as a part of the curriculum. Neverthe- less, students should also learn ways of thinking in nursing concepts rather than simply mastering knowledge. The traditional strategy for teaching is passive learning via lectures of knowledge, which for nursing students, is outdated. Students must become comfortable with the NCLEX-RN questions, which means being introduced to them early-on in their education. The university school of nursing has made several initiatives over two years to bring more of an active approach to NCLEX-RN preparation for students. They have added a regimen of standardized test-taking, and if a student is off-track, they are given multiple remediation opportunities to get back on track to pass the NCLEX-RN right after they graduate. Strategy is successful as NCLEX pass rate improved at the university school of nursing. Furthermore, continued study should be done concerning this balance of teaching and learning methods in relation to NCLEX-RN preparation methods and increasing pass rates.

\section{CONFLICTS OF INTEREST DISClOSURE}

The authors declare that there is no conflict of interest.

\section{REFERENCES}

[1] NCSBN: Examination test plan for the National Council Licensure Examination for Registered Nurses [Internet]. Chicago: National Council of State Boards of Nursing; c1978 [cited 2014 Jan]. Available from: https://www.ncsbn.org/testplans.htm

[2] NCSBN: Exam statistics \& publications [Internet]. Chicago: National Council of State Boards of Nursing; c1978 [cited 2015 Jan]. Available from: https://www.ncsbn.org/exam-statistics-and-pub lications.htm

[3] Carr SM. NCLEX-RN pass rate peril: One school's journey through curriculum revision, standardized testing, and attitudinal change. Nurse Education Prespective. 2011 Nov; 32(6): 384-388. https: //doi.org/10.5480/1536-5026-32.6.384

[4] March KS, Ambrose JM. Rx for NCLEX-RN success: Reflections on development of an effective preparation process for senior baccalaureate students. Nursing Education Perspective. 2010 Jul; 31(4): 230-232. PMid:20882863

[5] Bonis S, Taft L, Wendler MC. Strategies to promote success on the NCLEX-RN: An evidence-based approach using the ace star model of knowledge transformation. Nursing Education Perspectives. 2007 Mar; 28(2): 82-87.

[6] Carrick JK. Student achievement and NCLEX-RN success: Problems that persist. Nursing Education Perspectives. 2011 Mar; 32(2): 78-83.
PMid:21667787 https : //doi .org/10.5480/1536-5026-32.2. 78

[7] Johnson AN. NCLEX-RN success with boot camp: Western Governors University. Nursing Education Perspective. 2009 Sep; 30(5): 328-239. PMid:19824243

[8] Davenport NC. A comprehensive approach to NCLEX-RN success. Nursing Education Perspectives. 2007 Jan; 28(1): 30-33. PMid:17380959

[9] Hyland JR. Building on the evidence: Interventions promoting NCLEX success. Open Journal of Nursing. 2012 May; 2: 231-238. https://doi.org/10.4236/ojn.2012.23036

[10] Poorman S, Mastorovich M, Molcan K, et al. Decreasing performance and test anxiety in practicing nurses. Journal for Nurses in Staff Development. 2009; 25(1): 13-22. PMid:19182552 https: //doi.org/10.1097/NND.0b013e318194b4d7

[11] Barton L, Willson P, Langford R, et al. Standardized Predictive Testing: Practices, Policies, and Outcomes. Administrative Issues Journal: Education, Practice, and Research. 2014; 4(2): 68-76. https://doi.org/10.5929/2014.4.2.2

[12] Grubb N, Boner E, Frankel K, et al. Basic skills instruction in community colleges: The dominance of remedial pedagogy. Stanford: Policy Analysis for California Education (PACE); 2012.

[13] Arikian VP. Kaplan nursing: the basics. New York: Kaplan Publishing; 2016. 